\title{
Glue ear in adults, paediatric sleep apnoea and the nose in exercise
}

The puzzling condition of otitis media with effusion (OME) in adults is reviewed in this issue by Mills and Hathorn. ${ }^{1}$ This complements nicely recent articles by Wasson and Yung ${ }^{2}$ on the evidence-based management of otitis media (in its various forms) and the study from Dundee of sinonasal symptoms in patients with ear disease ${ }^{3}$ which confirmed the association between the two groups of conditions. The pathology of OME in children is far from clear, and as Mills and Hathorn point out, the situation in adults is no better, with many important gaps in our knowledge.

The more controversial subject of direct treatment of the eustachian tube with balloon dilatation is reviewed by Jufas and Patel, and appropriate caveats are applied in this tricky subject. ${ }^{4}$ Mitchell-Innes and colleagues have recently addressed the topic of otic barotrauma. ${ }^{5}$

Nasal physiology has featured strongly in The Journal of Laryngology \& Otology in the past, and Walker and colleagues' review of nasal function in exercise adds to this legacy admirably. ${ }^{6}$ The main points are not controversial in that area, but the recent paper by Ozturk et al. dispels the myth that dorsal nasal skin cooling has a physiological basis in the management of epistaxis, as nasal volume (determined by acoustic rhinometry) did not change after cold compresses were placed over the nasal dorsum. ${ }^{7}$

The topic of paediatric sleep apnoea continues to generate interest. The paper by Sharma et al. ${ }^{8}$ on trends in assessment and management fits in well with recent papers by Lightbody et al. ${ }^{9}$ on pre-operative overnight oximetry as a predictor of high dependency unit requirements and the multicentre study of the T14 outcome measure in paediatric patients by Hopkins et al. ${ }^{10}$

One predictable but disheartening finding by Vijendren et al. is that ENT surgeons have perhaps more than their fair share of musculoskeletal problems. ${ }^{11}$ This has implications for us all, and for the designers of equipment and operating theatre and clinic layouts, as the ergonomics of most ENT clinics leave a great deal to be desired.

EDWARD FISHER
ROBIN YOUNGS
MUSHEER HUSSAIN
JONATHAN FISHMAN
Senior Editors

References

1 Mills R, Hathorn I. Aetiology and pathology of otitis media with effusion in adult life. J Laryngol Otol 2016;130:418-24

2 Wasson JD, Yung MW. Evidence-based management of otitis media: a 5S model approach. J Laryngol Otol 2015;129:112-9

3 Yin B-S, Miah MS, Hussain SS. Sinonasal symptoms in adults with ear disease. J Laryngol Otol 2014;128:438-41

4 Jufas N, Patel N. Transtympanic balloon dilatation of the eustachian tube: systematic review. J Laryngol Otol 2016;130: $425-30$

5 Mitchell-Innes A, Young E, Vasiljevic A, Rashid M. Air travellers' awareness of the preventability of otic barotrauma. J Laryngol Otol 2014;128:494-8

6 Walker A, Surda P, Rossiter M, Little S. Nasal function and dysfunction in exercise. J Laryngol Otol 2016;130:431-4

7 Ozturk M, Mutlu F, Kara A, Derin S, Topdag M. Evaluation of the effect of nasal dorsal skin cooling on nasal mucosa by acoustic rhinometry. J Laryngol Otol 2014;128:1067-70

8 Sharma SD, Kanona H, Kumar G, Kotecha B. Latest trends in the assessment and management of paediatric snoring and sleep apnoea. J Laryngol Otol 2016;130:482-9

9 Lightbody KA, Kinshuk AJ, Donne AJ. Pre-operative overnight pulse oximetry to predict high dependency unit intervention in children undergoing adenotonsillectomy for obstructive sleep apnoea. J Laryngol Otol 2014;128:360-4

10 Hopkins C, Almeyda R, Alreefy H, Ismail-Koch H, Lim J, Possamai V et al. Multicentre prospective clinical application of the T14 paediatric outcome tool. J Laryngol Otol 2015; 129:980-5

11 Vijendren A, Yung M, Sanchez J, Duffield K. Occupational musculoskeletal pain amongst ENT surgeons - are we looking at the tip of an iceberg? J Laryngol Otol 2016;130:490-6 